\title{
Computer-aided Evaluation of Anti-SARS-CoV-2 (3- chymotrypsin-like Protease and Transmembrane Protease Serine 2 Inhibitors) Activity of Cepharanthine: An In silico Approach
}

\author{
Divya Jain ${ }^{1}$, Rajib Hossain ${ }^{2}$, Rasel Ahmed Khan ${ }^{3}$, Dipta Dey ${ }^{4}$, Tanzila Rahman Toma ${ }^{5}$, Mohammad \\ Torequl Islam ${ }^{2}$, Pracheta Janmeda ${ }^{1}$, Khalid Rehman Hakeem 6,* (D)
}

1 Department of Bioscience and Biotechnology, Banasthali Vidyapith, Rajasthan-304022, India; divyajain31011996@gmail.com; pracheta@banasthali.in (P.J.);

2 Department of Pharmacy, Life Science Faculty, Bangabandhu Sheikh Mujibur Rahman Science and Technology University, Gopalganj-8100, Bangladesh; rajibhossainrh021@gmail.com (R.H.); mti031124@gmail.com (M.T.I.);

3 Pharmacy Discipline, Life Science School, Khulna University, Khulna, Bangladesh; raselahmed358@gmail.com (R.A.K.);

4 Department of Biochemistry and Molecular Biology, Life Science Faculty, Bangabandhu Sheikh Mujibur Rahman Science and Technology University, Gopalganj-8100, Bangladesh; diptadey727@gmail.com (D.D.);

5 Institute of Social Welfare and Research, University of Dhaka, Dhaka, Bangladesh; tanzilarahman95t@gmail.com (T.R.T.);

6 Department of Biological Sciences, Faculty of Science, King Abdulaziz University, Jeddah, Saudi Arabia; kur.hakeem@gmail.com (K.R.H.);

* Correspondence: kur.hakeem@gmail.com;

Scopus Author ID 36993011800

Received: 28.02.2021; Revised: 4.04.2021; Accepted: 8.04.2021; Published: 26.04.2021

Abstract: 3-chymotrypsin-like protease $\left(3 \mathrm{CL}^{\mathrm{PRO}}\right)$ is found in severe acute respiratory syndrome coronavirus (SARS CoV)-2, and transmembrane protease serine 2 (TMPRSS-2) in humans, both of them have a role in viral attachment and proliferation. $3 \mathrm{CL}^{\mathrm{PRO}}$ and TMPRSS- 2 are the most vital target for the discovery of an anti-corona virus. One efficient approach used to screen potential active compounds against specific target proteins, such as $3 \mathrm{CL}^{\mathrm{PRO}}$ and TMPRSS-2, is molecular docking. Cepharanthine (CEP) exhibits antiviral activity in SARS-CoV at $9.5 \mu \mathrm{g} / \mathrm{mL} \mathrm{IC}_{50}$ level. This study aims to perform an in silico study on CEP against non-structural SARS-CoV-2 3CL ${ }^{\mathrm{PRO}}$ and host transmembrane protease serine 2 protein. Molecular docking studies were carried out using compounds against $3 \mathrm{CL}^{\text {PRO }}$ and TMPRSS-2 proteins through Swiss model, Uniport, PROCHECK, Swiss PDB viewer, PyMol, and PyRx computerized software. CEP displayed strong binding interactions -8.5 and $-7.4 \mathrm{Kcal} / \mathrm{mol}$ with the $3 \mathrm{CL}^{\mathrm{PRO}}$, and TMPRSS-2 proteins. In all cases, CEP showed better binding affinities than FDA-approved anti-corona virus drug (Camostat mesylate, CAM) is currently underused in COVID-19. CEP may be one of the potentials leads to fighting against SARS-CoV-2. Further in vivo studies should be required to support the findings of this study.

Keywords: Cepharanthine; COVID-19; 3CL ${ }^{\mathrm{PRO}}$;molecular docking; pkCSM, Swiss-ADME; TMPRSS2.

(C) 2021 by the authors. This article is an open-access article distributed under the terms and conditions of the Creative Commons Attribution (CC BY) license (https://creativecommons.org/licenses/by/4.0/).

\section{Introduction}

Novel coronavirus (Coronaviridae family) [1, 2] is a pathogenic microorganism that primarily targets the human respiratory tract, causing fever, fatigue, dry cough, muscle aches, 
shortness of breath, loss of taste or smell, headache, and sometimes pneumonia [3-5]. The severe acute respiratory syndrome coronavirus 2 (SARS CoV-2) is a single-stranded RNA virus along with 29,903 nucleotides base-pair genome sequence [6-9].

In 2019, coronavirus became a pandemic worldwide [10]. Two categories of proteins are identified in SARS CoV-2, includes structural proteins and non-structural proteins. In structural proteins involves Spike (S), Nucleocapsid (N), Matrix (M), and Envelope (E), and the non-structural proteins are 3- chymotrypsin-like protease $\left(3 \mathrm{CL}^{\mathrm{PRO}}\right)$, Papain-like protease $\left(\mathrm{PL}^{\mathrm{PRO}}\right)$, and RNA-dependent RNA polymerase (RdRp) [7]. The CoV-2 polyprotein encodes two protease- 3-chymotrypsin-like protease $\left(\mathrm{M}^{\mathrm{PRO}}\right.$ or $\left.3 \mathrm{CL}^{\mathrm{PRO}}\right)$ and papain-like protease ( $\mathrm{PL}{ }^{\mathrm{PRO}}$ ) [11], which are responsible for transcription and replication of the proteins in the viral genome [12].

It catalytically cleaved the conserved sites in polyprotein 1ab (PP1ab) and 1a (PP1a) [13]. The structure and catalytic mechanism of $3 \mathrm{CL}^{\mathrm{PRO}}$ consider it as a selective target for drug development for coronavirus. Coronavirus can synthesis a precursor protein, essential for virus fusion to the host cell membrane (human cell), cleavage by TMPRSS2 (a host cell proteases) $[14,15]$. Whereas the TMPRSS2 facilitates hCoVs, including SARS-CoV-2 infections, via two independent mechanisms: (i) proteolytic cleavage of hACE2R, which promotes viral uptake, and (ii) cleavage of CoV S proteins which activates the glycoprotein for host cell entry [16]. It has also been suggested that the intestine is one of the potential sites of SARS-CoV-2 replication. Besides, TMPRSS2 and TMPRSS4 were seen to facilitate SARS-CoV-2 spike fusogenic activity, thereby promoted virtual entrance into the host [17]. Hence, protease inhibitors should be the drug target for treating or preventing viral infections. On the other hand, serine protease inhibitors can suppress viral proliferation [18, 19].

Cepharanthine $\left(\mathrm{C} 37 \mathrm{H} 38 \mathrm{~N} 2 \mathrm{O}_{6}, \mathrm{CEP}\right)$ is a biscoclaurine alkaloid containing a methylenedioxy group [20, 21], isolated from Stephania [22]. Cepharanthine is a potential lead with significant antiviral activity against viruses, including HIV, HTLV, HBV, SARS-CoV. In SARS-CoV, Cepharanthine inhibits protease at $9.5 \mu \mathrm{g} / \mathrm{ML}$ [23]. Besides this, it has many important biological activities, such as antioxidant [24], anti-tumor [25], anti-inflammatory, antineoplastic [22], anticancer, anti-sicking [23], antiplasmodial [26] activities.

In exploring novel therapies for COVID-19, researchers use computational approaches to aid in discovering potential candidates [27-29]. Two essential strategies should be followed by the researcher for the development of new coronavirus drugs. Firstly, inhibitors should have the ability to block virus entry into the host cells, and secondly, compounds that attenuate viral transcription and cell replication. One efficient approach used to screen potential active compounds against specific target proteins, such as $3 \mathrm{CL}^{\mathrm{PRO}}$ and TMPRSS2 are molecular docking simulation. Therefore, these are important targets for the design of potential anti-CoV inhibitors.

\section{Materials and Methods}

\subsection{Computational homology modeling and macromolecule preparation.}

For modeling, the sequence of $3 \mathrm{CL}^{\mathrm{PRO}}$, and TMPRSS2 were poised from UniProt [30] followed by BLAST analysis using the NCBI BLAST program [31]. Computational homology modeling was carried out by Swissmodel [32]. Then, to validate the homology model acquired from the Swiss model, PROCHECK [33] online-based software was employed. After that, with these protein model docking was performed for binding interactions. A swiss-PDB Viewer 
software package (version 4.1.0) was utilized for energy minimization of structures, and before docking, PyMOl (version 1.7.4.5) was performed for removing all the heteroatoms and water molecules from proteins [34].

\subsection{Ligand preparation.}

The ligands, Cepharanthine (CEP) (PubChem ID: 10206) and FDA-approved antiviral drugs Camostat mesylate (CAM) (PubChem ID: 5284360) (Figure 1) were downloaded from the PubChem in the 'sdf' file format. Using Chem3D Pro12.0 program packages [35], all internal energies of the ligands molecule were optimized. The Nation Centre maintains the system for Biotechnology Information (NCBI), a component of the National Library of Medicine.
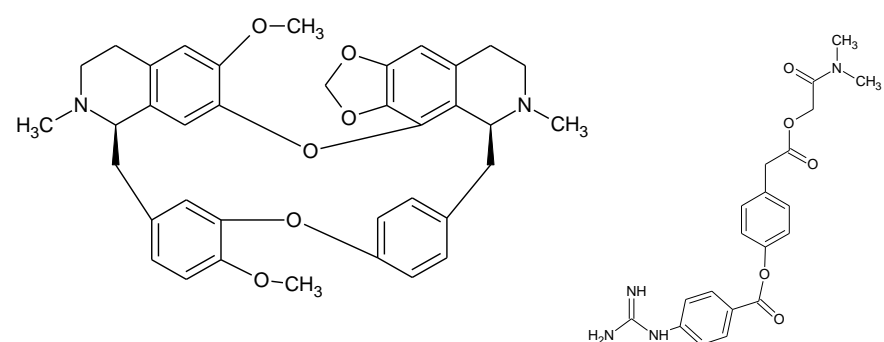

Cepharanthine

Camostat mesylate

Figure 1. The chemical structure of Cepharanthine and Camostat mesylate (drawn by chem sketch v12.1.0.31258).

\subsection{Docking analysis and binding site.}

In drug discovery and development study, molecular docking is a system that is used for predicting the drug candidate's pharmacodynamics profile by scoring and orienting them to the receptor binding sites by PyRx-virtual screening tool [36]. The docking result determines the measure of ligand interaction to the active site of the targeted protein. The actives sites are the coordinates of the ligand in the original target protein grids [37] through PyMol and Drug Discovery Studio version 4.5 is used for scrutinizing these active binding sites of the target protein [38].

\subsection{ADMET prediction.}

Various pharmacokinetic properties (absorption, distribution, metabolism, excretion, and toxicity parameters) of CEP were predicted using pkCSM and Swiss ADME online-based computer software $[39,40]$. The ADMET parameters of CEP were mainly analyzed. The website was logged on and the SMILES of CEP data from PubChem were searched and submitted to the website, ADMET mode in pkCSM, and ADME mode in Swiss-ADME was selected.

\subsection{Target prediction.}

For discovering and developing a drug, it has been important to find the phenotypical side effects or potential cross-reactivity for bioactive compounds. For finding side effects or cross-reactivity, Molecular Target studies are essential [41, 42]. Swiss Target Prediction is an online-based website. For searching the targets, the canonical SMILES of CEP were entered into the search bar and were analyzed. 


\section{Results and Discussion}

\subsection{Homology modeling.}

The SARS CoV-2 3CL ${ }^{\text {PRO }}$ (Uniprot accession ID: P0DTD1), and TMPRSS2 (Uniprot accession ID: O15393) amino acid were collected from, were subjected to NCBI Blast Program for selection of the closest homologous template Homology model of $3 \mathrm{CL}^{\mathrm{PRO}}$, and TMPRSS2 was generated by Swiss model (Figure 2). Optimization of $3 \mathrm{CL}^{\mathrm{PRO}}$ and TMPRSS2 was achieved using the Swiss-PDB Viewer software package (version 4.1.0) before docking. At the same time, validation of these $3 \mathrm{CL}^{\mathrm{PRO}}$, and TMPRSS2 homology models were acquired through the use of the Ramachandran plot performed by PROCHECK and illustrated in Figure 3.

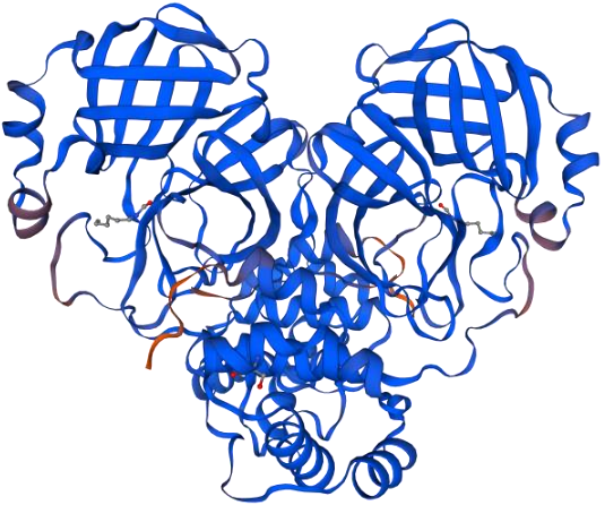

(a)

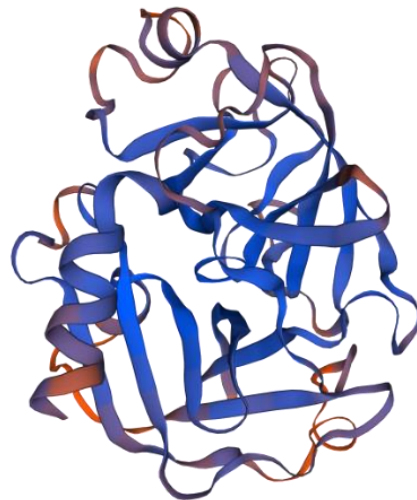

(b)

Figure 2. Three-dimensional structures of the (a), SARS-CoV-2 3CLPRO, and (b). TMPRSS2 is predicted by the Swiss model.

\subsection{Amino acid interaction of Cepharanthine and Camostat mesylate with SARS-CoV-2} $3 C L^{P R O}$, and human TMPRSS-2.

Today, anti-corona virus drugs are the crying need for treating COVID-19. So many people have died for SARS-CoV-2 worldwide. Several antiviral drugs like Ritonavir, Lopinavir, Indinavir, and Remdesivir, and Camostat mesylate are used for the trial to possess a cure for showing the anti-Coronavirus effect [43]. But in some emergency cases, hydroxychloroquine and azithromycin are shown potent effects [44-46], but the complex showed adverse side effects. An equally or more potent natural compound should be found out by researchers that are safe and have fewer side effects. Cepharanthine is an excellent candidate for anti-Coronavirus agents because of its biological properties. It can be isolated from Stephania [22].

$3 \mathrm{CL}^{\mathrm{PRO}}$ can provide a transcript and replicate the viral genome [12], whereas the TMPRSS2 facilitates hCoVs, including SARS-CoV-2 infections, via two independent mechanisms. First, it promotes viral uptake through proteolytic cleavage of hACE2R, and secondly, cleavage of CoV-2 Spike proteins [16].

The reference inhibitor's interactions and selected biscoclaurine alkaloid with 3chymotrypsin-like protease $\left(3 \mathrm{CL}^{\mathrm{PRO}}\right)$ of coronaviruses and human transmembrane protease serine-2 (TMPRSS-2)are represented in Table 1. The ligand molecule mostly exhibited interaction with target proteins amino acid residues through hydrophobic interactions. Some H-bonding was also seen, but it was Carbon-Hydrogen interaction. 


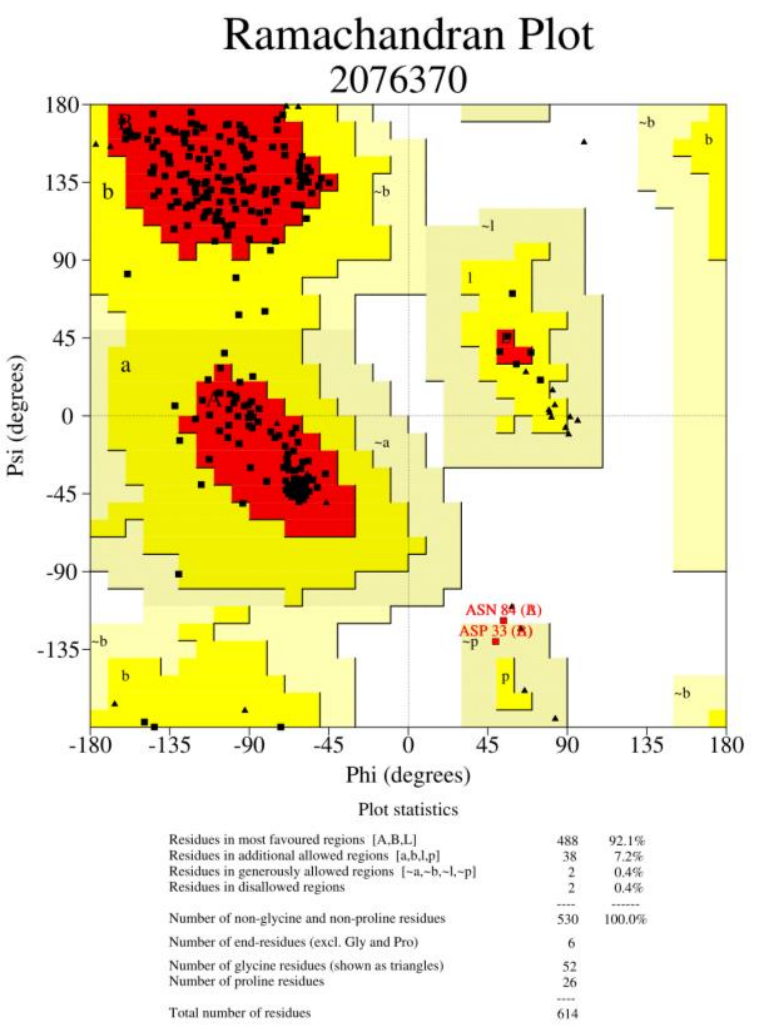

a) $3 \mathrm{CL}^{\mathrm{PRO}}$

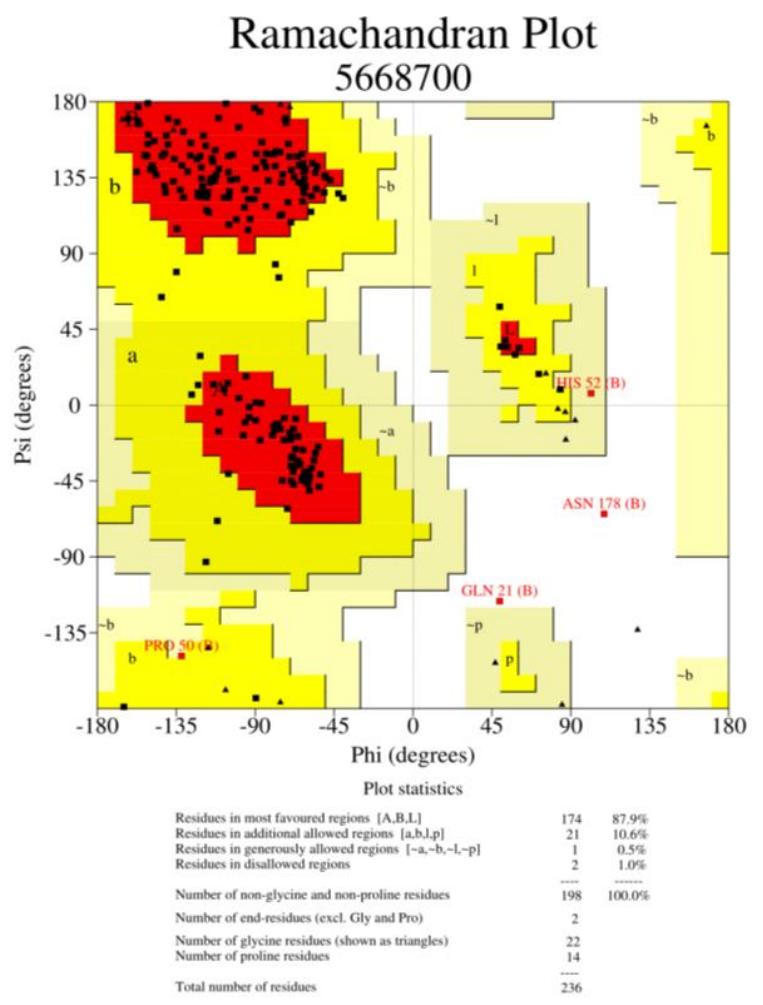

b) TMPRSS2

Figure 3. The optimized model of the SARS CoV-2 (a) $3 \mathrm{CL}^{\mathrm{PRO}}$ and (b) human TMPRSS-2 using PROCHECK.

The ligand-protein binding interactions analysis showed CEPexhibited good binding affinities -8.5 and $-7.4 \mathrm{kcal} / \mathrm{mol}$ with $3 \mathrm{CL}^{\mathrm{PRO}}$ and TMPRSS-2, respectively. It showed binding interactions with $3 \mathrm{CL}^{\mathrm{PRO}}$ through four bonds like carbon-hydrogen, alkyl, and pi-alkyl, with Ile249and Pro293, and Pi-anion with Asp245 amino acid residues. Besides, with TMPRSS-2, CEP interacts through Lys107, Trp198, Cys110, Ile197, Lys107, Pro13, Trp14amino acids in the receptor pocket. Two carbon-hydrogen bonds with Lys107, trp198 amino acid residues and $\pi-S, \pi-\pi, \pi$-alkyl bonds with Cys110, Trp14, Ile197, Lys107, Pro13, respectively.

In a computational molecular docking study, CEP is successfully docked against $3 \mathrm{CL}^{\mathrm{PRO}}$, and TMPRSS2 inhibitor regions with a docking score of -8.5 and $-7.4 \mathrm{Kcal} / \mathrm{mol}$, respectively. Furthermore, it exerts good binding affinities compared with lopinavir, oseltamivir, and ritonavir, whose binding affinities are $-4.1 \mathrm{Kcal} / \mathrm{mol},-4.65 \mathrm{Kcal} / \mathrm{mol}$, and -5.11 $\mathrm{Kcal} / \mathrm{mol}$ [47]. Moreover, some plant-derived flavonoid and polyphenolic compounds such as kaempferol, quercetin, demethoxycurcumin, curcumin, catechin, epicatechingallate, gingerol, and gingerolcan inhibit the main protease of SARS-CoV-2 in silico study whose binding affinities are $-9.41 \mathrm{Kcal} / \mathrm{mol},-8.58 \mathrm{Kcal} / \mathrm{mol},-8.17 \mathrm{Kcal} / \mathrm{mol},-7.31 \mathrm{Kcal} / \mathrm{mol},-7.05 \mathrm{Kcal} / \mathrm{mol}$, - 7.24 Kcal/mol, $-6.67 \mathrm{Kcal} / \mathrm{mol}$ and $-5.40 \mathrm{Kcal} / \mathrm{mol}$ respectively.

Table 1. Docking results of cepharanthine (CEP) and reference compound, camostat mesylate (CAM) with the SARS-CoV2 $\left(3 C L^{P R O}\right)$, and human TMPRSS2 proteins therapeutic target.

\begin{tabular}{c|c|c|l} 
Drug-Protein complex & Docking score $\mathbf{( k c a l / m o l )}$ & No of H-Bond & Amino acid residues \\
\hline CEP-3CL $^{\text {PRO }}$ & -8.5 & 1 & Ile249 (H), Pro293, Asp245. \\
\hline CEP-TMPRSS2 & -7.4 & 2 & $\begin{array}{l}\text { Lys107 (H), Trp198 (H), Cys110, } \\
\text { Ile197, Lys107,Pro13,Trp14. }\end{array}$ \\
\hline CAM-3CL ${ }^{\text {PRO }}$ & -7.4 & 4 & $\begin{array}{l}\text { Asp153 (H), Asn151 (H), Ile249(H), } \\
\text { Ser158(H), Ile106, Phe294. }\end{array}$ \\
\hline CAM-TMPRSS2 & -7.4 & 2 & $\begin{array}{l}\text { Lys68 (H), Asp67, Ile135, Leu132, } \\
\text { Phe66, Phe118, Pro53. }\end{array}$
\end{tabular}



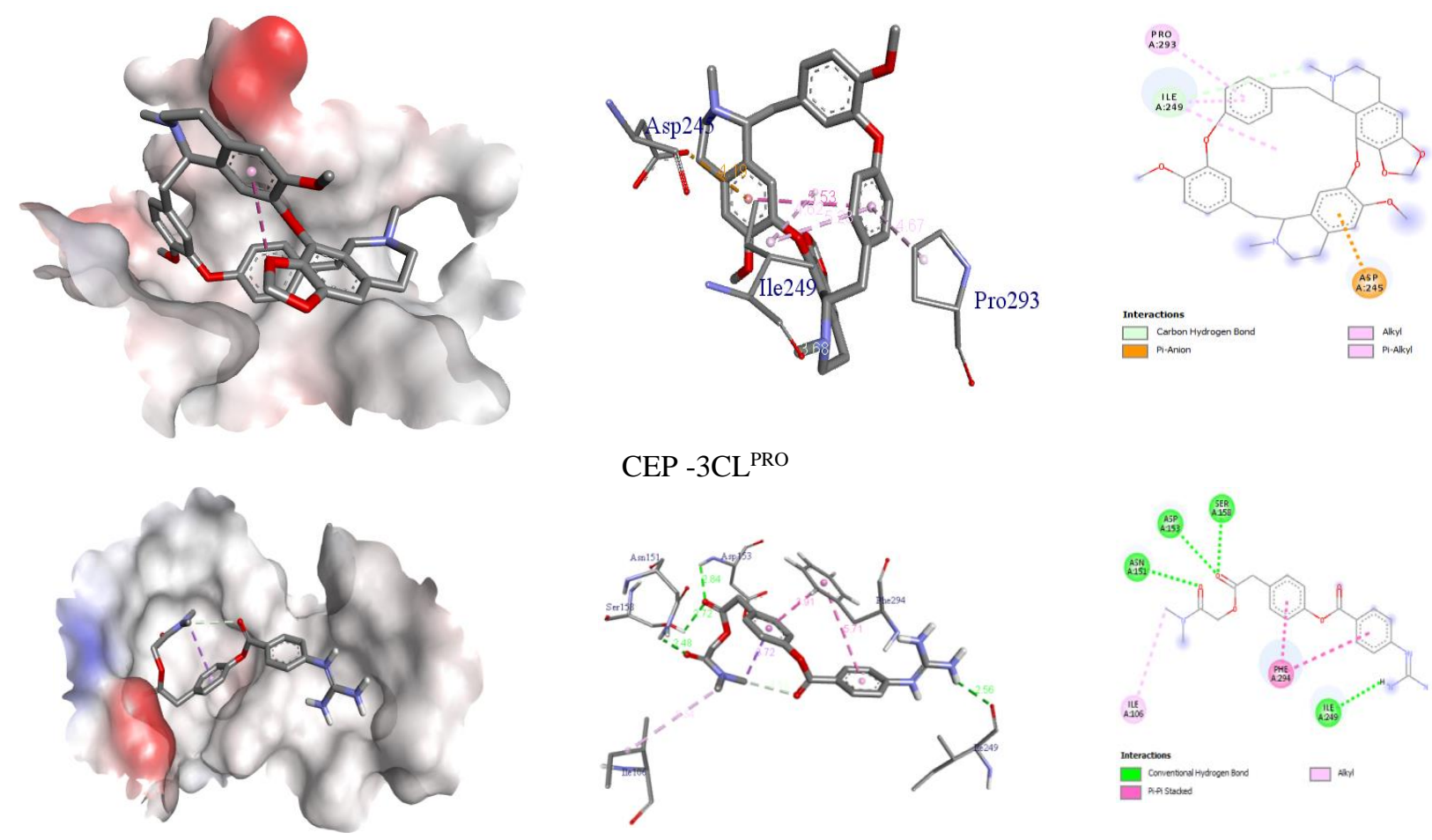

CEP $-3 C L^{\text {PRO }}$
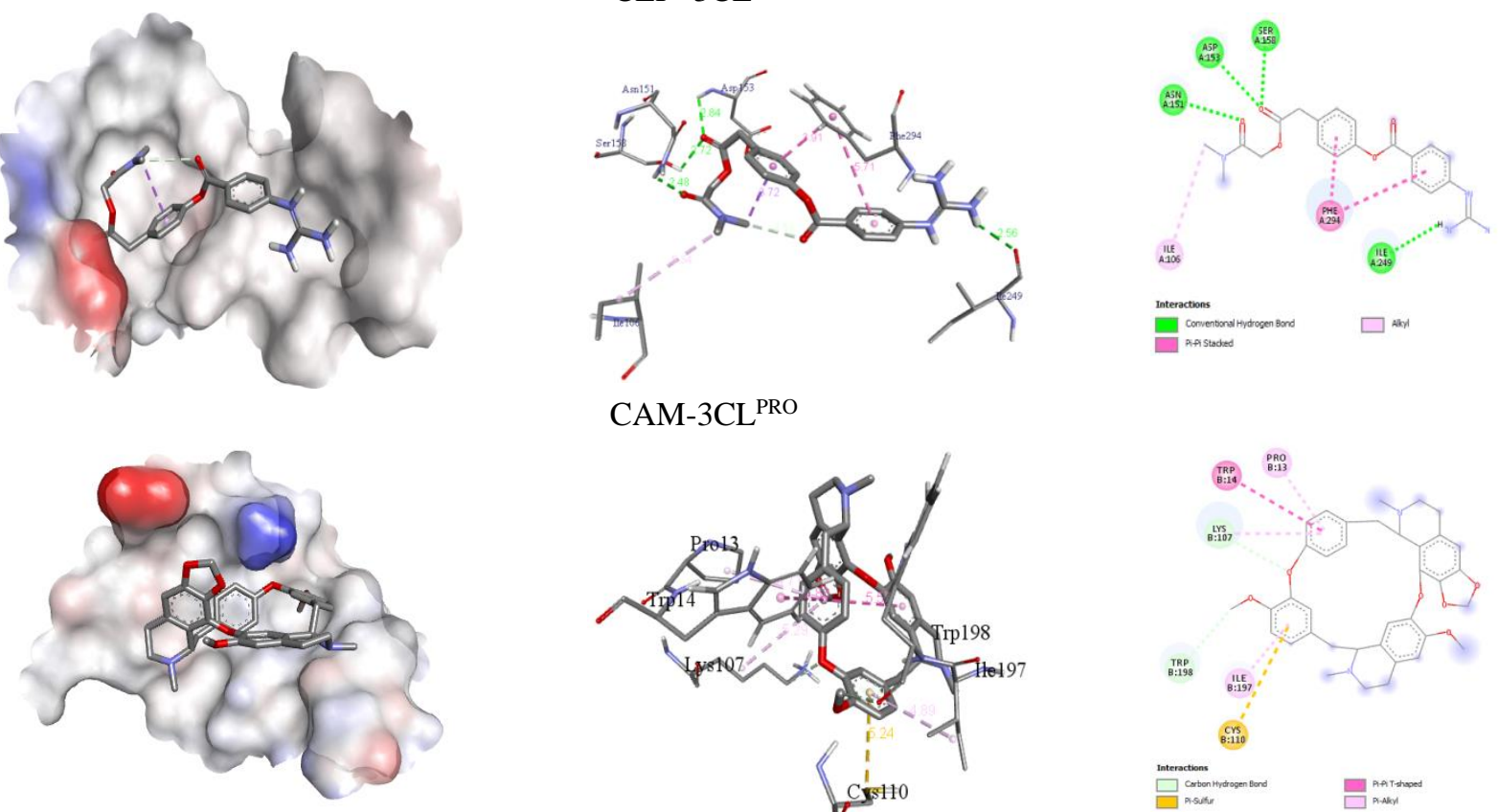

CAM-3CL ${ }^{\text {PRO }}$
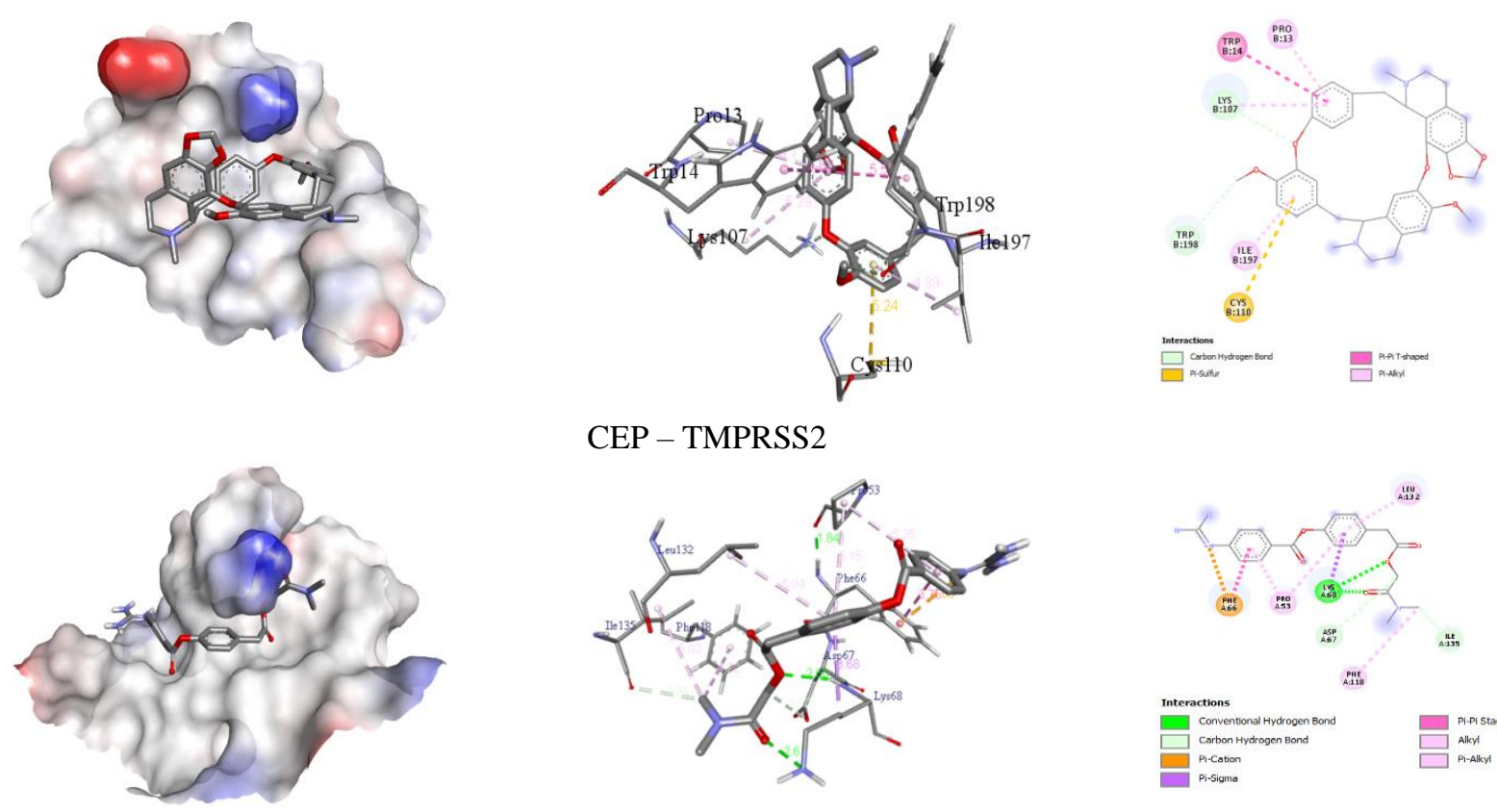

CEP - TMPRSS2
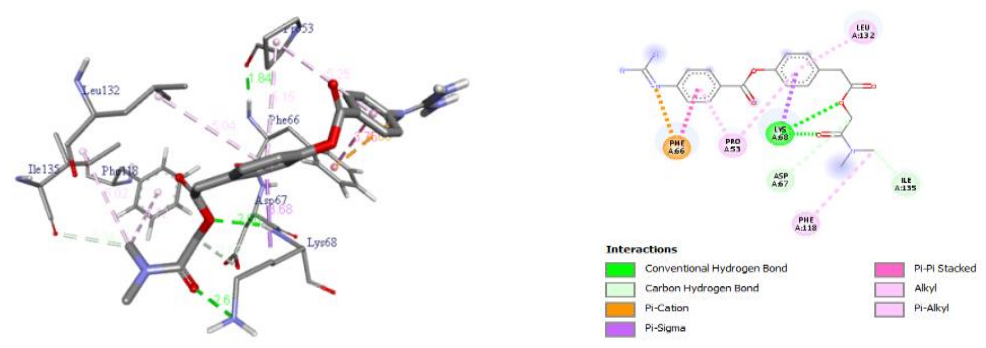

CAM - TMPRSS2

Figure 4. Interactions of cepharanthine (CEP) and camostat mesylate (CAM) with the SARS-CoV-2 and host proteins (TMPRSS-2).

In this study, the docking score of cepharanthine is higher. Even the proposed inhibitor of SARS CoV-2, such as camostat mesylate, has a docking score of $-7.4 \mathrm{Kcal} / \mathrm{mol}$, which claimed that CEP has better properties than camostatmesylate and other combinations therapy. A study suggested that CEP at $9.5 \mu \mathrm{g} / \mathrm{mL}$ IC50 concentration inhibits SARS CoV protease [48].

Camostat mesylate (CAM) is a synthetic compound used as a serine protease inhibitor $[49,50]$, which was first mentioned in the literature in 1981, as askin tumors inhibitors in mice models. Furthermore, it can inhibit cholecystokinin, pro-inflammatory cytokines, and serine proteases and treat COVID-19 [51-53]. 
On the other hand, the standard drug (Camostat mesylate, CAM) showed good binding interaction $(-7.4 \mathrm{kcal} / \mathrm{mol})$ with $3 \mathrm{CL}^{\mathrm{PRO}}$ and TMPRSS2 (Table 1). The hydroxyl group of Asp153, Asn151, Ile249, Ser158 at a distance of 2.48, 2.84, 2.56, and 2.72 , respectively, while the $\pi-\pi$ interaction of Phe294 and alkyl interaction of Ile106 exhibiting hydrophobic interaction. Similarly, the hydroxyl group of CAM also mediates two hydrogen bond interactions with Lys68 with a distance of 2.60 and $2.61 \AA$ with TPMPRSS-2 receptor amino acids. Additionally, multiple hydrophobic interactions were observed with Asp67, Ile135, Leu132, Phe66, Phe118, and Pro53. The 2D and 3D structures of non-bond interactions of CEP and CAM with the target proteins have been illustrated in Figure 4.

\subsection{Physiochemical, pharmacokinetics, and toxicological properties assessment of CEP.}

From online-based software data, it has been found that CEP has a molecular weight of $606.71 \mathrm{~g} / \mathrm{mol}$ with 45 heavy atoms and 0.35 Fraction Csp3 (Figure 5). It has 2 rotatable bonds, 8 H-bond acceptors but no H-bond donors. Molar refractivity is 179.15 , and TPSA is $61.86 \AA^{2}$. The molecule's lipophilicity in terms of $\log P_{\mathrm{o} / \mathrm{w}}(\mathrm{iLOGP}), \quad \log P_{\mathrm{o} / \mathrm{w}}(\mathrm{XLOGP} 3)$, $\log P_{\mathrm{o} / \mathrm{w}}(\mathrm{WLOGP}), \log P_{\mathrm{o} / \mathrm{w}}(\mathrm{MLOGP}), \log P_{\mathrm{o} / \mathrm{w}}(\operatorname{SILICOS}-\mathrm{IT})$ was found 5.06, 6.54, 5.46, 3.96 and 5.71 respectively. It's a poorly soluble material with $\log S$ (ESOL) value of -7.98 and solubility value of $6.29 \mathrm{e}-06 \mathrm{mg} / \mathrm{ml} ; 1.04 \mathrm{e}-08 \mathrm{~mol} / \mathrm{l}$.

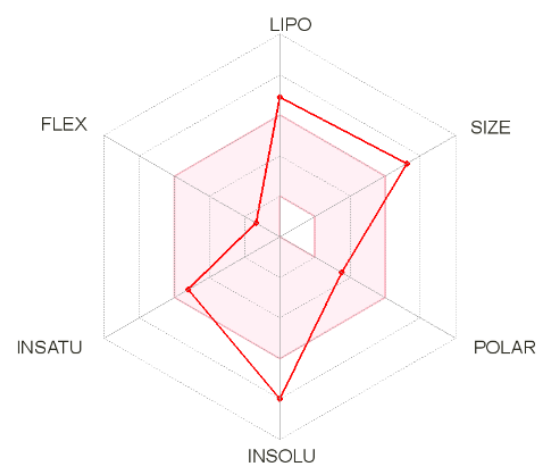

The color space is a suitable physiochemical space for oral bioavailability.

LIPO Lipophility: $-0.7<$ XLOGP3 < p5.0.

SIZE: $150 \mathrm{~g} / \mathrm{mol}<\mathrm{MW}<500 \mathrm{~g} / \mathrm{mol}$.

POLAR (Polarity): 20 $\AA^{2}<$ TPSA $<130 \AA^{2}$

INSOLU (insolubility): $0<\log \mathrm{S}(\mathrm{ESOL})<6$.

INSATU (insaturation): $0.25<$ Fraction Csp3 $<1$.

FLEX (Flexibity): $0<$ Num. rotatable bonds $<9$

Figure 5. Summary of physiochemical, pharmacokinetics, and toxicological properties of Cepharanthine.

In the computational docking study, CEP displayed good interaction with TMPRSS2 and inhibit serine protease. Some studies suggested that CEP is an antioxidant and antiinflammatory agent. It can attenuate oxidative stress and inflammation in several testing systems [22, 24]. Additionally, CEP is cytotoxic effects on the existing viruses [54, 55]. Therefore, CEP should have cytotoxic effects on the existing SARS CoV-2. When a compound has followed four basic criteria, it should be an ideal anti-COVID-19 drug. CEP can restrict viral entrance by inhibiting cellular attachment. It can attenuate viral replication and cytotoxic effects on the existing viruses. And finally, it can protect the normal host cells from the viral origin oxidative stress and inflammatory responses, and CEP meets all the requirements. 
Several studies suggested that small molecules should have $<500 \mathrm{gm} / \mathrm{mol}$ for acceptability, for considering a drug, whereas CEP has a slightly higher molecular weight. A range of $\mathrm{H}$-bond acceptors and $\mathrm{H}$-bond donors with $\leq 10$ and $\leq 5$ are acceptable. It has also been suggested that the molar refractivity of compounds ranging from 40-130, lipophilicity (LogP) is $<5$ is accepted.

CEP shows high GI absorption without any BBB permeation, P-gp substrate, and CYP50 inhibitor, whereas Log $K_{\mathrm{p}}$ (skin permeation) is $-5.36 \mathrm{~cm} / \mathrm{s}$. In terms of drug-likeness CEP complies with Lipinski's rule of five, showing 1 violation $(M W>500)$, which violates 3 parameters of the Ghose rule (MW>480, MR>130, \#atoms $>70$ ), complies to Veber and Egan rules. $\mathrm{CEP}$ has 3 violations of Muegge rule (No; 3 violations: MW>600, XLOGP3>5, \#rings $>7)$. The bioavailability score CEP is 0.55 . The compound has shown zero PAINS and Brenk alert. It showed 2 violations in the Leadlikeness score $(\mathrm{MW}>350$, XLOGP3>3.5) along with 7.01 synthetic accessibility (Table 2 ).

Table 2. Predicted Physiochemical, drug-likeness, and ADME properties of the selected compound by Swiss ADME.

Physicochemical Properties

\begin{tabular}{|c|c|}
\hline Molecular weight & $606.71 \mathrm{~g} / \mathrm{mol}$ \\
\hline Num. heavy atoms & 45 \\
\hline Fraction Csp3 & 0.35 \\
\hline Num. rotatable bonds & 2 \\
\hline Num. H-bond acceptors & 8 \\
\hline Num. H-bond donors & 0 \\
\hline Molar Refractivity & 179.15 \\
\hline TPSA & $61.86 \AA^{2}$ \\
\hline \multicolumn{2}{|r|}{ Lipophilicity } \\
\hline $\log P_{\mathrm{o} / \mathrm{w}}(\mathrm{iLOGP})$ & 5.06 \\
\hline $\log P_{\mathrm{o} / \mathrm{w}}(\mathrm{XLOGP} 3)$ & 6.54 \\
\hline $\log P_{\mathrm{o} / \mathrm{w}}($ WLOGP) & 5.46 \\
\hline $\log P_{\mathrm{o} / \mathrm{w}}(\mathrm{MLOGP})$ & 3.96 \\
\hline $\log P_{\mathrm{o} / \mathrm{w}}($ SILICOS-IT) & 5.71 \\
\hline \multicolumn{2}{|r|}{ Water Solubility } \\
\hline $\log S(\mathrm{ESOL})$ & -7.98 \\
\hline Solubility & $6.29 \mathrm{e}-06 \mathrm{mg} / \mathrm{ml} ; 1.04 \mathrm{e}-08 \mathrm{~mol} / \mathrm{l}$ \\
\hline Class & Poorly soluble \\
\hline \multicolumn{2}{|r|}{ Pharmacokinetics } \\
\hline GI absorption & High \\
\hline BBB permeant & No \\
\hline P-gp substrate & No \\
\hline CYP50 inhibitor & No \\
\hline Log $K_{\mathrm{p}}$ (skin permeation) & $-5.36 \mathrm{~cm} / \mathrm{s}$ \\
\hline \multicolumn{2}{|r|}{ Drugl-ikeness } \\
\hline Lipinski & Yes; 1 violation: $M W>500$ \\
\hline Ghose & No; 3 violations: $M W>480, M R>130$, \#atoms $>70$ \\
\hline Veber & Yes \\
\hline Egan & Yes \\
\hline Muegge & No; 3 violations: $M W>600$, XLOGP3>5, \#rings $>7$ \\
\hline Bioavailability Score & 0.55 \\
\hline \multicolumn{2}{|c|}{ Medicinal Chemistry } \\
\hline PAINS & 0 alert \\
\hline Brenk & 0 alert \\
\hline Leadlikeness & No; 2 violations: $M W>350$, XLOGP3>3.5 \\
\hline Synthetic accessibility & 7.01 \\
\hline
\end{tabular}

Upon toxicity testing, CEP displayed positive AMES toxicity also; the tolerable maximum tolerable dose in humans is $0.232 \mathrm{mg} / \mathrm{kg} / \mathrm{day}$. It has shown no hERG I inhibitor activity but shown hERG II inhibitor activity. The LD50 value for oral rat acute toxicity is 2.554, and the LOAEL value is 0.711 while showing no hepatotoxicity and skin sensitization (Table 3). 
The drug-likeness evaluates the probability for a molecule to turn an oral drug concerning bioavailability. The Lipinski is the pioneer rule of five [56], and the Ghose, Veber, Egan, and Muegge were performed in case of drug-likeness [57-60]. The Bioavailability Score pursues to compute a compound's probability to have oral bioavailability in rat or measurable Caco-2 permeability [61]. Here, PAINS are the molecules carrying substructures exhibiting optimal response in assays irrespective of the protein target [62-64].

Brenk et al., [62] reported a list of 105 fragments for the structural alert. Our study revealed zero alerts of PAINS and Brenk. Leadlikeness is subjected to chemical modifications that can enhance the size and lipophilicity of the compound, and the leads are requisite to be lesser and small hydrophobicity [65]. Synthetic accessibility (SA), in the selection of suitable virtual molecules, is a chief factor. Medicinal chemists, for a reasonable number of molecules, are the best able to determine SA. The SA Score ranges from 1-10 (very easy-very difficult to synthesize), after normalization [66]. Moreover, it has no hepatotoxicity and skin sensitization.

Table 3. Toxicological properties of Cepharanthine.

\begin{tabular}{l|l|l|l} 
Property & Model Name & Predicted Value & Unit \\
\hline \multirow{5}{*}{ Toxicity } & AMES toxicity & Yes & Categorical (Yes/No) \\
\cline { 2 - 4 } & Max. tolerated dose (human) & $\mathbf{0 . 2 3 2}$ & Numeric (log mg/kg/day) \\
\cline { 2 - 4 } & hERG I inhibitor & No & Categorical (Yes/No) \\
\cline { 2 - 4 } & hERG II inhibitor & Yes & Categorical (Yes/No) \\
\cline { 2 - 4 } & Oral Rat Acute Toxicity (LD50) & $\mathbf{2 . 5 5 4}$ & Numeric $(\mathrm{mol} / \mathrm{kg})$ \\
\cline { 2 - 4 } & Oral Rat Chronic Toxicity (LOAEL) & $\mathbf{0 . 7 1 1}$ & Numeric $(\log \mathrm{mg} / \mathrm{kg} \mathrm{bw} / \mathrm{day})$ \\
\cline { 2 - 4 } & Hepatotoxicity & No & Categorical (Yes/No) \\
\cline { 2 - 4 } & Skin Sensitisation & No & Categorical (Yes/No)
\end{tabular}

\subsection{Target prediction.}

The pie chart is the best way to display several subjects at a time. For target prediction analysis, the top 15 of the results were given as pie-chart are illustrated in figure 6 . The pie chart displayed $40 \%$ of family A G protein-coupled receptor, $13.3 \%$ of electrochemical transporter, $6.7 \%$ of Hydrolasse, phosphodiesterase, membrane receptor, and $26.7 \%$ of a ligand-gated ion channel. The Target, Common Name, Uniprot ID, ChEMBL-ID, Target Class, Probability, and Known actives in 2D/3D are given in the output table.

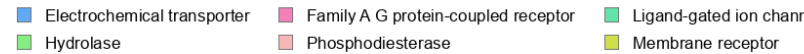

Figure 6. Top-15 of Target Predicted for Cepharanthine.

Furthermore, target prediction data suggested that if cepharanthine showed any adverse pharmacological effect in the testing system, where are the possible binds create with the target by Cepharanthine. It has been predicted that cepharanthine is most probably bound with familyA $\mathrm{G}$ protein-coupled receptor, electrochemical transporter, hydrolases, phosphodiesterase, membrane receptor, and ligand-gated ion channel. 
From the predicted in silico, physiochemical, drug-likeness, and ADME properties, target prediction test data, it has been claimed that CEP is a good candidate for COVID-19 treatment.

\section{Conclusions}

In summary, the computer-aided analysis was performed for elucidating the activity of cepharanthine, which was found in the Stephania plant and could treat SARS-CoV-2 3CL ${ }^{\text {PRO }}$ and human TMPRSS-2 targets. Cepharanthine should be possibly used as a lead compound and neutraceuticals involved in COVID-19 treatment. Although further in vivo studies are necessary to establish the findings observed in this study, our findings will help further nonclinical, pre-clinical, and clinical studies with this compound. Finally, this study will inspire medicinal scientists to conduct adequate research on this hopeful natural lead compound and its laboratory derivatives.

\section{Funding}

This research received no external funding.

\section{Acknowledgments}

The authors acknowledge the Bioinformatics Centre, Banasthali Vidyapith supported by DBT and DST for providing computation and networking support through the FIST and CURIE programs at the Department of Bioscience and Biotechnology, Banasthali Vidyapith, Rajasthan, India, and special thanks to the International Centre for Empirical Research and Development (ICERD), and Department of Pharmacy, Life Science Faculty, Bangabandhu Sheikh Mujibur Rahman Science and Technology University, Gopalganj, Bangladesh.

\section{Conflicts of Interest}

The authors declare no conflict of interest.

\section{References}

1. Boopathi, S.; Poma, A. B.; Kolandaivel, P. Novel 2019 Coronavirus Structure, Mechanism of Action, Antiviral Drug Promises and Rule out against Its Treatment. J. Biomol. Struct. Dyn 2020, 1-10, https://doi.org/10.1080/07391102.2020.1758788.

2. Li, F. Structure, Function, and Evolution of Coronavirus Spike Proteins. Annu. Rev. Virol 2016, 3, 237-261, https://doi.org/10.1146/annurev-virology-110615-042301.

3. Rothan, H.A.; Byrareddy, S.N. The Epidemiology and Pathogenesis of Coronavirus Disease (COVID-19) Outbreak. J. Autoimmun 2020, 109, https://doi.org/10.1016/j.jaut.2020.102433.

4. Ebrahimi, A. Correlation of CoViD-19 Infection and Tumorigenesis. Letters in Applied NanoBioScience 2021, 10, 2578-2587, https://doi.org/10.33263/LIANBS103.25782587.

5. Cheke, R.S.; Narkhede, R.R.; Shinde, S.D.; Ambhore, J.P.; Jain, P.G. Repurposing of Anthelmintic Drugs against SARS-CoV-2 (Mpro and RdRp): Novel Disease, Older Therapeutics. Lett. Appl. NanoBioScience 2021, 10, 2331-2338.

6. Masters, P.S. The Molecular Biology of Coronaviruses. Adv. Virus Res 2006, 66, 193-292, https://dx.doi.org/10.1016\%2FS0065-3527(06)66005-3.

7. Elfiky, A.A.; Mahdy, S.M.; Elshemey, W.M. Quantitative Structure-Activity Relationship and Molecular Docking Revealed a Potency of Anti-Hepatitis C Virus Drugs against Human Corona Viruses. J. Med. Virol 2017, 89, 1040-1047. https://doi.org/10.1002/jmv.24736.

8. Padhy, M. A Review on Medicinal Plants Withania Somnifera and Nyctanthes Arbortristis: Boosting of Immune System During SARS-CoV-2. Lett. Appl. NanoBioScience 2020, 9, 1538-1546, https://doi.org/10.33263/LIANBS94.15381546. 
9. Krishnakumar, S.; Aabha Benjamin, G. P. W. Outbreak, Prevalence and Mortality of Severe Acute Respiratory Syndrome (SARS-CoV-2) Infections in Kerala- A Perspective Study. Lett. Appl. NanoBioScience 2021, 10, 2016-2023, https://doi.org/10.33263/LIANBS101.20162023.

10. Francés-Monerris, A.; Hognon, C.; Miclot, T.; García-Iriepa, C.; Iriepa, I.; Terenzi, A.; Grandemange, S.; Barone, G.; Marazzi, M.; Monari, A. Molecular Basis of SARS-CoV-2 Infection and Rational Design of Potential Antiviral Agents: Modeling and Simulation Approaches. J. Proteome Res 2020, 19, 4291-4315, https://dx.doi.org/10.1021/acs.jproteome.0c00779

11. Hilgenfeld, R. From SARS to MERS: Crystallographic Studies on Coronaviral Proteases Enable Antiviral Drug Design. FEBS J 2014, 281, 4085-4096, https://doi.org/10.1111/febs.12936.

12. Gyebi, G.A.; Ogunro, O.B.; Adegunloye, A.P.; Ogunyemi, O.M.; Afolabi, S.O. Potential Inhibitors of Coronavirus 3-Chymotrypsin-like Protease (3CLpro): An in Silico Screening of Alkaloids and Terpenoids from African Medicinal Plants. J. Biomol. Struct. Dyn 2020, 1-13, https://doi.org/10.1080/07391102.2020.1764868.

13. Anand, K.; Ziebuhr, J.; Wadhwani, P.; Mesters, J.R.; Hilgenfeld, R. Coronavirus Main Proteinase (3CLpro) Structure: Basis for Design of Anti-SARS Drugs. Science 2003, 300, 1763-1767, https://doi.org/10.1126/science.1085658.

14. Böttcher-Friebertshäuser, E.; Freuer, C.; Sielaff, F.; Schmidt, S.; Eickmann, M.; Uhlendorff, J.; Steinmetzer, T.; Klenk, H.-D.; Garten, W. Cleavage of Influenza Virus Hemagglutinin by Airway Proteases TMPRSS2 and HAT Differs in Subcellular Localization and Susceptibility to Protease Inhibitors. J. Virol 2010, 84, 5605-5614, https://doi.org/10.1128/jvi.00140-10.

15. Yamaya, M.; Shimotai, Y.; Hatachi, Y.; Lusamba Kalonji, N.; Tando, Y.; Kitajima, Y.; Matsuo, K.; Kubo, H.; Nagatomi, R.; Hongo, S.; Homma, M.; Nishimura, H. The Serine Protease Inhibitor Camostat Inhibits Influenza Virus Replication and Cytokine Production in Primary Cultures of Human Tracheal Epithelial Cells. Pulm. Pharmacol. Ther 2015, 33, 66-74, https://doi.org/10.1016/j.pupt.2015.07.001.

16. Shulla, A.; Heald-Sargent, T.; Subramanya, G.; Zhao, J.; Perlman, S.; Gallagher, T. A Transmembrane Serine Protease Is Linked to the Severe Acute Respiratory Syndrome Coronavirus Receptor and Activates Virus Entry. J. Virol 2011, 85, 873-882, https://doi.org/10.1128/JVI.02062-10.

17. Zang, R.; Gomez Castro, M.F.; McCune, B.T.; Zeng, Q.; Rothlauf, P.W.; Sonnek, N.M.; Liu, Z.; Brulois, K.F.; Wang, X.; Greenberg, H.B.; Diamond, M.S.; Ciorba, M.A.; Whelan, S.P.J.; Ding, S. TMPRSS2 and TMPRSS4 Promote SARS-CoV-2 Infection of Human Small Intestinal Enterocytes. Sci. Immunol 2020, 5 , https://doi.org/10.1126/sciimmunol.abc3582.

18. Böttcher, E.; Freuer, C.; Steinmetzer, T.; Klenk, H.-D.; Garten, W. MDCK Cells That Express Proteases TMPRSS2 and HAT Provide a Cell System to Propagate Influenza Viruses in the Absence of Trypsin and to Study Cleavage of $\mathrm{HA}$ and Its Inhibition. Vaccine 2009, 27, 6324-6329, https://doi.org/10.1016/j.vaccine.2009.03.029.

19. Böttcher-Friebertshäuser, E.; Stein, D. A.; Klenk, H.-D.; Garten, W. Inhibition of Influenza Virus Infection in Human Airway Cell Cultures by an Antisense Peptide-Conjugated Morpholino Oligomer Targeting the Hemagglutinin-Activating Protease TMPRSS2. J. Virol 2011, 85, 1554-1562.

20. Rogosnitzky, M.; Danks, R. Therapeutic Potential of the Biscoclaurine Alkaloid, Cepharanthine, for a Range of Clinical Conditions. Pharmacol. Rep 2011, 63, 337-347, https://doi.org/10.1016/S1734-1140(11)70500$\mathrm{X}$.

21. Rogosnitzky, M.; Okediji, P.; Koman, I. Cepharanthine: A Review of the Antiviral Potential of a JapaneseApproved Alopecia Drug in COVID-19. Pharmacol. Rep 2020, 72, 1509-1516, https://doi.org/10.1007/s43440-020-00132-z.

22. Huang, H.; Hu, G.; Wang, C.; Xu, H.; Chen, X.; Qian, A. Cepharanthine, an Alkaloid from Stephania Cepharantha Hayata, Inhibits the Inflammatory Response in the RAW264. 7 Cell and Mouse Models. Inflammation 2014, 37, 235-246, https://doi.org/10.1007/s10753-013-9734-8.

23. Jeon, S.; Ko, M.; Lee, J.; Choi, I.; Byun, S. Y.; Park, S.; Shum, D.; Kim, S. Identification of Antiviral Drug Candidates against SARS-CoV-2 from FDA-Approved Drugs. Antimicrob. Agents Chemother 2020, 64, https://doi.org/10.1128/AAC.00819-20.

24. Gülçin, I.; Elias, R.; Gepdiremen, A.; Chea, A.; Topal, F. Antioxidant Activity of Bisbenzylisoquinoline Alkaloids from Stephania Rotunda: Cepharanthine and Fangchinoline. J. Enzyme Inhib. Med. Chem 2010, 25, 44-53, https://doi.org/10.3109/14756360902932792.

25. Seubwai, W.; Vaeteewoottacharn, K.; Hiyoshi, M.; Suzu, S.; Puapairoj, A.; Wongkham, C.; Okada, S.; Wongkham, S. Cepharanthine Exerts Antitumor Activity on Cholangiocarcinoma by Inhibiting NF- $\mathrm{B}$. Cancer science 2010, 101, 1590-1595, https://doi.org/10.1111/j.1349-7006.2010.01572.x.

26. Desgrouas, C.; Chapus, C.; Desplans, J.; Travaille, C.; Pascual, A.; Baghdikian, B.; Ollivier, E.; Parzy, D.; Taudon, N. In Vitro Antiplasmodial Activity of Cepharanthine. Malar. J 2014, 13, https://doi.org/10.1186/1475-2875-13-327.

27. Ciliberto, G.; Cardone, L. Boosting the Arsenal against COVID-19 through Computational Drug Repurposing. Drug Discov. Today 2020, 25, 946-948, https://doi.org/10.1016/j.drudis.2020.04.005. 
28. Ruan, Z.; Liu, C.; Guo, Y.; He, Z.; Huang, X.; Jia, X.; Yang, T. SARS-CoV-2 and SARS-CoV: Virtual Screening of Potential Inhibitors Targeting RNA-Dependent RNA Polymerase Activity (NSP12). J. Med. Virol 2021, 93, 389-400, https://doi.org/10.1002/jmv.26222.

29. Vyshnava, S.S.; Kanderi, D.K.; Panjala, S.P.; Paramasivam, K.; Pandluru, G.; Banapuram, S.; Anupalli, R.R.; Dowlatabad, M.R. A Computational Approach on the Activity of Hesperidin as Antagonist for Proteins of SARS-CoV-2. Lett. Appl. NanoBioScience 2021, 10, 2571-2577.

30. UniProt Consortium. UniProt: A Hub for Protein Information. Nucleic Acids Res 2015, 43, D204-212, https://doi.org/10.1093/nar/gku989.

31. Johnson, M.; Zaretskaya, I.; Raytselis, Y.; Merezhuk, Y.; McGinnis, S.; Madden, T.L. NCBI BLAST: A Better Web Interface. Nucleic Acids Res 2008, 36, W5-9, https://doi.org/10.1093/nar/gkn201.

32. Biasini, M.; Bienert, S.; Waterhouse, A.; Arnold, K.; Studer, G.; Schmidt, T.; Kiefer, F.; Gallo Cassarino, T.; Bertoni, M.; Bordoli, L.; Schwede, T. SWISS-MODEL: Modelling Protein Tertiary and Quaternary Structure Using Evolutionary Information. Nucleic Acids Res 2014, 42, W252-8, https://doi.org/10.1093/nar/gku340.

33. Laskowski, R.A.; MacArthur, M.W.; Thornton, J.M. PROCHECK: Validation of Protein-Structure Coordinates. In International Tables for Crystallography; International Union of Crystallography: Chester, England, 2012, 684-687, https://doi.org/10.1107/97809553602060000882.

34. Yuan, S.; Chan, H.C.S.; Hu, Z. Using PyMOL as a Platform for Computational Drug Design: PyMOL: Platform for Computational Drug Design. Wiley Interdiscip. Rev. Comput. Mol. Sci 2017, 7, https://doi.org/10.1002/wcms.1298.

35. Rahman, A.; Ali, M.T.; Shawan, M.M.A.K.; Sarwar, M.G.; Khan, M.A.K.; Halim, M.A. Halogen-Directed Drug Design for Alzheimer's Disease: A Combined Density Functional and Molecular Docking Study. Springerplus 2016, 5, https://doi.org/10.1186/s40064-016-2996-5.

36. Ekins, S.; Mestres, J.; Testa, B. In Silico Pharmacology for Drug Discovery: Methods for Virtual Ligand Screening and Profiling. Br. J. Pharmacol 2007, 152, 9-20, https://doi.org/10.1038/sj.bjp.0707305.

37. Fukunishi, Y.; Nakamura, H. Prediction of Ligand-Binding Sites of Proteins by Molecular Docking Calculation for a Random Ligand Library: Prediction of Ligand-Binding Sites. Protein Sci 2011, 20, 95106,https://doi.org/10.1002/pro.540.

38. Kar, S.; Roy, K. How Far Can Virtual Screening Take Us in Drug Discovery? Expert Opin. Drug Discov 2013, 8, 245-261, https://doi.org/10.1517/17460441.2013.761204.

39. Pires, D.E.V.; Blundell, T.L.; Ascher, D.B. PkCSM: Predicting Small-Molecule Pharmacokinetic and Toxicity Properties Using Graph-Based Signatures. J. Med. Chem 2015, 58, 4066-4072, https://doi.org/10.1021/acs.jmedchem.5b00104.

40. Daina, A.; Michielin, O.; Zoete, V. SwissADME: A Free Web Tool to Evaluate Pharmacokinetics, DrugLikeness and Medicinal Chemistry Friendliness of Small Molecules. Sci. Rep 2017, 7, https://doi.org/10.1038/srep42717.

41. Keiser, M.J.; Roth, B.L.; Armbruster, B.N.; Ernsberger, P.; Irwin, J.J.; Shoichet, B.K. Relating Protein Pharmacology by Ligand Chemistry. Nat. Biotechnol 2007, 25, 197-206, https://doi.org/10.1038/nbt1284.

42. Gfeller, D.; Grosdidier, A.; Wirth, M.; Daina, A.; Michielin, O.; Zoete, V. SwissTargetPrediction: A Web Server for Target Prediction of Bioactive Small Molecules. Nucleic Acids Res 2014, 42, W32-8, https://doi.org/10.1093/nar/gku293.

43. Nejadi Babadaei, M. M.; Hasan, A.; Vahdani, Y.; Haj Bloukh, S.; Sharifi, M.; Kachooei, E.; Haghighat, S.; Falahati, M. Development of Remdesivir Repositioning as a Nucleotide Analog against COVID-19 RNA Dependent RNA Polymerase. J. Biomol. Struct Dyn 2020, 1-9, https://doi.org/10.1080/07391102.2020.1767210.

44. Heald-Sargent, T.; Gallagher, T. Ready, Set, Fuse! The Coronavirus Spike Protein and Acquisition of Fusion Competence. Viruses 2012, 4, 557-580, https://dx.doi.org/10.3390/v4040557.

45. Vincent, M.J.; Bergeron, E.; Benjannet, S.; Erickson, B.R.; Rollin, P.E.; Ksiazek, T.G.; Seidah, N.G.; Nichol, S.T. Chloroquine Is a Potent Inhibitor of SARS Coronavirus Infection and Spread. Virol. J 2005, 2, https://doi.org/10.1186/1743-422X-2-69.

46. Wang, M.; Cao, R.; Zhang, L.; Yang, X.; Liu, J.; Xu, M.; Shi, Z.; Hu, Z.; Zhong, W.; Xiao, G. Remdesivir and Chloroquine Effectively Inhibit the Recently Emerged Novel Coronavirus (2019-NCoV) in Vitro. Cell Res 2020, 30, 269-271, https://doi.org/10.1038/s41422-020-0282-0.

47. Muralidharan, N.; Sakthivel, R.; Velmurugan, D.; Gromiha, M.M. Computational Studies of Drug Repurposing and Synergism of Lopinavir, Oseltamivir and Ritonavir Binding with SARS-CoV-2 Protease against COVID-19. J. Biomol. Struct. Dyn 2020, 39,1-6, https://doi.org/10.1080/07391102.2020.1752802.

48. Khaerunnisa, S.; Kurniawan, H.; Awaluddin, R.; Suhartati, S.; Soetjipto, S. Potential Inhibitor of COVID19 Main Protease (Mpro) From Several Medicinal Plant Compounds by Molecular Docking Study. Preprints 2020, https://doi.org/10.20944/preprints202003.0226.v1.

49. Midgley, I.; Hood, A.J.; Proctor, P.; Chasseaud, L.F.; Irons, S.R.; Cheng, K.N.; Brindley, C.J.; Bonn, R. Metabolic Fate of 14C-Camostat Mesylate in Man, Rat and Dog after Intravenous Administration. Xenobiotica 1994, 24, 79-92, https://doi.org/10.3109/00498259409043223. 
50. Kitamura, K.; Tomita, K. Proteolytic Activation of the Epithelial Sodium Channel and Therapeutic Application of a Serine Protease Inhibitor for the Treatment of Salt-Sensitive Hypertension. Clin. Exp. Nephrol.2012, 16, 44-48, https://doi.org/10.1007/s10157-011-0506-1.

51. Göke, B.; Printz, H.; Koop, I.; Rausch, U.; Richter, G.; Arnold, R.; Adler, G. Endogenous CCK Release and Pancreatic Growth in Rats after Feeding a Proteinase Inhibitor (Camostate). Pancreas 1986, 1, 509-515, https://doi.org/10.1097/00006676-198611000-00008.

52. Jia, D.; Taguchi, M.; Otsuki, M. Synthetic Protease Inhibitor Camostat Prevents and Reverses Dyslipidemia, Insulin Secretory Defects, and Histological Abnormalities of the Pancreas in Genetically Obese and Diabetic Rats. Metabolism 2005, 54, 619-627, https://doi.org/10.1016/j.metabol.2004.12.005.

53. Hoffmann, M.; Kleine-Weber, H.; Schroeder, S.; Krüger, N.; Herrler, T.; Erichsen, S.; Schiergens, T.S.; Herrler, G.; Wu, N.-H.; Nitsche, A.; Müller, M.A.; Drosten, C.; Pöhlmann, S. SARS-CoV-2 Cell Entry Depends on ACE2 and TMPRSS2 and Is Blocked by a Clinically Proven Protease Inhibitor. Cell 2020, 181, 271-280.e8, https://doi.org/10.1016/j.cell.2020.02.052.

54. Okamoto, M.; Ono, M.; Baba, M. Potent Inhibition of HIV Type 1 Replication by an Antiinflammatory Alkaloid, Cepharanthine, in Chronically Infected Monocytic Cells. AIDS Res. Hum. Retroviruses 1998, 14, 1239-1245, https://doi.org/10.1089/aid.1998.14.1239.

55. Matsuda, K.; Hattori, S.; Komizu, Y.; Kariya, R.; Ueoka, R.; Okada, S. Cepharanthine Inhibited HIV-1 CellCell Transmission and Cell-Free Infection via Modification of Cell Membrane Fluidity. Bioorg. Med. Chem. Lett 2014, 24, 2115-2117, https://doi.org/10.1016/j.bmcl.2014.03.041.

56. Lipinski, C.A.; Lombardo, F.; Dominy, B.W.; Feeney, P.J. Experimental and Computational Approaches to Estimate Solubility and Permeability in Drug Discovery and Development Settings. Adv. Drug Deliv. Rev 2012, 46, 4-17, https://doi.org/10.1016/s0169-409x(00)00129-0.

57. Ghose, A.K.; Viswanadhan, V.N.; Wendoloski, J.J.A Knowledge-Based Approach in Designing Combinatorial or Medicinal Chemistry Libraries for Drug Discovery. 1. A Qualitative and Quantitative Characterization of Known Drug Databases. J. Comb. Chem 1999, 1, 55-68, https://doi.org/10.1021/cc9800071.

58. Egan, W.J.; Merz, K.M.Jr.; Baldwin, J.J. Prediction of Drug Absorption Using Multivariate Statistics. J. Med. Chem. 2000, 43, 3867-3877, https://doi.org/10.1021/jm000292e.

59. Muegge, I.; Heald, S. L.; Brittelli, D. Simple Selection Criteria for Drug-like Chemical Matter. J. Med. Chem. 2001, 44, 1841-1846, https://doi.org/10.1021/jm015507e.

60. Veber, D.F.; Johnson, S.R.; Cheng, H.-Y.; Smith, B.R.; Ward, K.W.; Kopple, K.D. Molecular Properties That Influence the Oral Bioavailability of Drug Candidates. J. Med. Chem. 2002, 45, 2615-2623, https://doi.org/10.1021/jm020017n.

61. Martin, Y.C. A Bioavailability Score. J. Med. Chem. 2005, 48, 3164-3170, https://doi.org/10.1021/jm0492002

62. Brenk, R.; Schipani, A.; James, D.; Krasowski, A.; Gilbert, I.H.; Frearson, J.; Wyatt, P.G. Lessons Learnt from Assembling Screening Libraries for Drug Discovery for Neglected Diseases. ChemMedChem. 2008, 3 , 435-444, https://doi.org/10.1002/cmdc.200700139.

63. Baell, J.B.; Holloway, G.A. New Substructure Filters for Removal of Pan Assay Interference Compounds (PAINS) from Screening Libraries and for Their Exclusion in Bioassays. J. Med. Chem. 2010, 53, 27192740, https://doi.org/10.1021/jm901137j.

64. Hann, M.M.; Keserü, G.M. Finding the Sweet Spot: The Role of Nature and Nurture in Medicinal Chemistry. Nat. Rev. Drug Discov. 2012, 11, 355-365,https://doi.org/10.1038/nrd3701.

65. Maideen, N.M.P. Recent Updates in the Pharmacological Management of COVID-19. Lett Appl NanoBioSci2020, 10, 1969-1980, https://doi.org/10.33263/LIANBS101.19691980.

66. Ertl, P.; Schuffenhauer, A. Estimation of Synthetic Accessibility Score of Drug-like Molecules Based on Molecular Complexity and Fragment Contributions. J. Cheminform. 2009, 1, https://doi.org/10.1186/17582946-1-8. 